\title{
QUALITY ASPECTS OF PORK MEAT AND ITS NUTRITIONAL IMPACT
}

\author{
Fidel Toldrá, Miguel A. Rubio, José L. Navarro and Lucio Cabrerizo ${ }^{1}$
}

\section{INTRODUCTION}

Pork meat production in Europe has followed a steady increase over the last decade, with about 19,000,000 tonnes produced in 1,999, and is expected to remain fairly stable or even experiment a small increase over the next few years. Spain constitutes the second largest producer of pigmeat in the European Union. The production has risen to about 2,900,000 tonnes in 1,999. Pork meat is recognised as an important part of the European diet. However, consumers perception in recent years is not so good because they believe pork meat contains a high amount of visible fat with a high content in saturated fatty acids and cholesterol.

Modern pig breeding and feeding techniques is leading to a leaner meat with an increased proportion of unsaturated fatty acids in its lipids. In fact, the composition in fatty acids mainly depends on the genetic origin, age, weight at slaughter, feed composition and husbandry systems (Morgan et al., 1992; Toldrá et al., 1996). In some studies, the effect of genetics on intramuscular fat is broken down into free fatty acids, triglycerides and phospholipids (Gandemer et al., 1992; Armero et al., 2001). These authors found a strong effect of genetic type on the fatty acid composition of phospholipids but only a slight effect on the composition of triglycerides. Other studies have evaluated the effect of different pig sire types and sex on carcass traits and meat quality (Armero et al., 1999a) as well as on endogenous enzymatic activity such as cathepsins and exopeptidases (Armero et al, 1999b, 1999c). Fatty acid composition is also affected by the anatomical location of the muscle, especially the phospholipid fraction which contributes to the muscle variability (Leseigneur-Meynier and Gandemer, 1991; Hernández et al., 1998). In the case of feed, the change of the fatty acid composition in a monogastric animal such as pork is relatively easy.

Different pork meats, resulting from different crossbreeds and feeds, have been assayed in our laboratory during the last years for quality $(\mathrm{pH}$, color, drip loss and fat

${ }^{1}$ Fidel Toldrá and José L. Navarro, Instituto de Agroquímica y Tecnología de Alimentos (CSIC), PO Box 73, 46100 Burjassot (Valencia), Spain. Miguel A. Rubio and Lucio Cabrerizo, Endocrinología y Nutrición, Hospital Clínico San Carlos, Madrid, Spain 
content) and composition in fatty acids of polar and non-polar lipids. This work presents the results obtained with the crossbreed and feed which gave the best results in both quality and proportion in unsaturated fatty acids. The selected crossbreed was based on a Landrace $\mathrm{x}$ Large White pig and the feed consisted in a mixture of barley, wheat, corn and soya meal. This meat, which is branded as Porcidiet $^{\circledR}$ and commercialized by Vaquero Meat Industries, has also been chosen for studying its nutritional impact in a controlled diet with $<10 \%$ saturated fat and $<300 \mathrm{mg} / \mathrm{d}$ of cholesterol.

\section{TECHNOLOGICAL QUALITY}

Pork quality may experience large variations in quality depending on the susceptibility to stress. So, two extremes of quality like pale, soft and exudative (PSE) and dark, firm and dry (DFD) are usually found (Kauffman et al., 1993). The classification is usually based on $\mathrm{pH}$, measured at 2 and 24 hours postmortem in the muscle Semimembranosus, color parameter (L) and drip loss (DL). Thus, the carcasses from the selected crossbreed were classified according to the following values (Kauffman et al., 1993; Flores et al., 1999):

Pale, soft, exudative (PSE)

Red, firm, non-exudative (RFN)

Dark, firm, dry (DFD)

$$
\begin{aligned}
& \mathrm{pH}_{2 \mathrm{~h}}<5.8, \mathrm{~L}>50, \mathrm{DL}>6 \% \\
& \mathrm{pH}_{2 \mathrm{~h}}>5.8, \mathrm{pH}_{24 \mathrm{~h}}<6.0,44<\mathrm{L}<50, \mathrm{DL}<6 \% \\
& \mathrm{pH}_{24 \mathrm{~h}}>6.0, \mathrm{~L}<44, \mathrm{DL}>3 \%
\end{aligned}
$$

Based on these parameters, $82 \%$ of the carcasses were classified as normal (RFN), 15\% as PSE and only 3\% DFD. This postmortem quality has also an effect on the most important eating quality properties: tenderness and flavor. In the case of tenderness, it appears that DFD meat is more tender while PSE remains controversial (Tornberg, 1966; Flores et al., 1999). In the case of flavor, DFD meat also shows a good quality with a low sour and salty tastes and high sweet taste (Flores et al., 1999). In any case, PSE meat presents a high percentage of dripping that causes unsatisfaction to consumers.

The selected crossbreed showed a low intramuscular fat content and a relatively low content in cholesterol (see table 1). These results are thus in accordance to the dietary recommendations for a reduced intake of fat and cholesterol with an adequate fatty acid composition.

Table 1. Characteristics, expressed as means (X) and standard deviations (SD), of the muscle Longissimus dorsi.

\begin{tabular}{lcc}
\hline & $\mathrm{X}$ & $\mathrm{SD}$ \\
\hline Moisture $(\mathrm{g} / 100 \mathrm{~g})$ & 75.6 & 0.51 \\
Protein $(\mathrm{g} / 100 \mathrm{~g})$ & 21.8 & 2.1 \\
Total lipid $(\mathrm{g} / 100 \mathrm{~g})$ & 2.86 & 0.35 \\
Phospholipids $(\mathrm{g} / 100 \mathrm{~g})$ & 0.529 & 0.042 \\
Free fatty acids $(\mathrm{g} / 100 \mathrm{~g})$ & 0.025 & 0.005 \\
Triglycerides $(\mathrm{g} / 100 \mathrm{~g})$ & 2.31 & 0.221 \\
Cholesterol $(\mathrm{mg} / 100 \mathrm{~g})$ & 46.1 & 6.1 \\
\hline
\end{tabular}




\section{LIPIDS COMPOSITION}

\section{1.- Intramuscular lipids}

The composition in fatty acids of the muscle Longissimus dorsi is shown in table 2. These lipids can be separated into polar and non-polar lipids. The neutral fraction containing non-polar lipids averages for more than $80 \%$ of the total lipids while the polar lipids are constituted mostly by phospholipids (see table 1). The composition in fatty acids of both fractions is shown in table 2. Oleic acid, which is considered as a cholesterol lowering fatty acid, constitutes the major fatty acid (36.6\%). This fatty acid is especially present in the neutral fraction $(42.4 \%)$. When considering the saturated fatty acids and cardiovascular diseases, they contribute to the increase in LDL cholesterol but the individual fatty acids do not contribute to the same extent. For instance, myristic and palmitic acids $(1.5 \%$ and $25.1 \%$, respectively) raise LDL cholesterol while stearic acid $(12.7 \%)$ is considered to have no net effect. So, even though total SFA amounts for $39.3 \%$, only $26.6 \%$ are really contributing to the increase in LDL cholesterol. The ratios $\mathrm{M} / \mathrm{S}$ and $\mathrm{P} / \mathrm{S}$ are 1.01 and 0.53 , respectively. The last one is above the recommended ratio 0.45 (Enser et al., 1996).

Table 2. Fatty acid composition (expressed as \% of total fatty acids) of muscle Longissimus dorsi as well as into its neutral and polar fractions. Results expressed as means $(\mathrm{X})$ and standard deviations (SD)

\begin{tabular}{lllllll}
\hline \multicolumn{1}{r}{ Fatty acid } & \multicolumn{2}{c}{ Muscle } & \multicolumn{2}{c}{ Neutral } & \multicolumn{2}{c}{ Polar } \\
\hline C 14:0 & X & SD & X & SD & X & SD \\
C 16:0 & 1.55 & 0.32 & 1.97 & 0.33 & 0.32 & 0.06 \\
C 18:0 & 25.10 & 0.86 & 26.19 & 1.53 & 22.10 & 1.41 \\
C 16:1 & 12.62 & 0.44 & 11.91 & 0.82 & 14.49 & 0.61 \\
C 18:1 & 2.79 & 0.36 & 3.49 & 0.55 & 0.69 & 0.11 \\
C 20:1 & 36.47 & 2.85 & 42.35 & 2.53 & 11.45 & 0.77 \\
C 18:2 & 0.47 & 0.06 & 0.52 & 0.07 & 0.15 & 0.06 \\
C 18:3 & 16.49 & 2.87 & 11.38 & 3.08 & 37.37 & 1.38 \\
C 20:2 & 1.14 & 0.28 & 1.17 & 0.31 & 0.97 & 0.13 \\
C 20:3 & 0.49 & 0.08 & 0.43 & 0.09 & 0.66 & 0.12 \\
C 20:4 & 0.30 & 0.06 & 0.10 & 0.03 & 1.04 & 0.16 \\
C 22:4 & 2.18 & 0.38 & 0.25 & 0.07 & 9.83 & 1.06 \\
Total SFA & 0.25 & 0.04 & 0.08 & 0.02 & 0.84 & 0.17 \\
Total MUFA & 39.42 & 0.91 & 40.23 & 1.42 & 37.03 & 1.24 \\
Total PUFA & 39.74 & 3.15 & 46.36 & 2.93 & 12.26 & 0.85 \\
Ratio M/S & 20.84 & 3.58 & 13.41 & 3.56 & 50.70 & 1.50 \\
Ratio P/S & 1.01 & & 1.15 & & 0.33 & \\
$\sum \omega-3$ & 0.53 & & 0.33 & & 1.37 & \\
$\sum \omega-6$ & 1.14 & & 1.17 & & 0.97 & \\
$\sum \omega-6 / \Sigma \omega-3$ & 18.97 & & 11.73 & & 48.2 & \\
\hline & 16.64 & & 10.0 & & 49.7 & \\
\hline
\end{tabular}


Linolenic acis is the main source of $\omega-3$ acids while linoleic and arachidonic acids constitute the major $\omega-6$. Other $\omega-3$ fatty acids like eicosapentaenoic (EPA) and docosahexaenoic (DHA) acids are present only in a very low percentage (data not shown). The $\omega-6 / \omega-3$ ratio is proposed to be between 4 to 8 (Jakobsen, 1999).

Muscle tissue contains several endogenous antioxidant systems responsible for the oxidative stability of the lipids. Some of these antioxidants include histidinecontaining dipeptides carnosine and anserine. Their concentrations in the muscle are in the range $300-320 \mathrm{mg} / 100 \mathrm{~g}$ and $14-16 \mathrm{mg} / 100 \mathrm{~g}$, respectively (Aristoy and Toldrá, 1998). However, these values experience a high drop in the case of oxidative muscles. For further protection against oxidation, it is recommended to add vitamin $\mathrm{E}$ in the feed, at least 100-200 ppm for several weeks.

\section{2.- Adipose tissue lipids}

The composition in fatty acids of the adipose tissue is shown in table 3 . This composition tends to reflect the dietary fatty acids during fattening. The major fatty acid is oleic acid (31.64\%) followed by linoleic acid (25.39\%). The M/S and P/S ratios are 0.91 and 0.79 , respectively. The $\mathrm{P} / \mathrm{S}$ ratio is also quite above the recommended value 0.45 and approaching to 1.0 as the ultimate goal. Furthermore, the $\Sigma \omega-6 / \Sigma \omega-3$ is approaching the recommended range 4-8.

Table 3. Fatty acid composition (expressed as \% of total fatty acids) of adipose tissue. Results expressed as means (X) and standard deviations (SD).

\begin{tabular}{lll}
\hline \multicolumn{1}{c}{ Fatty acid } & & Adipose tissue \\
\hline C $14: 0$ & $\mathrm{X}$ & SD \\
C $16: 0$ & 1.40 & 0.17 \\
C $18: 0$ & 23.78 & 1.90 \\
C $16: 1$ & 11.67 & 1.17 \\
C $18: 1$ & 1.71 & 0.30 \\
C $20: 1$ & 31.64 & 3.57 \\
C $18: 2$ & 0.45 & 0.07 \\
C 18:3 & 25.39 & 5.05 \\
C 20:2 & 2.64 & 0.51 \\
C 20:3 & 0.78 & 0.09 \\
C 20:4 & 0.10 & 0.03 \\
C 22:4 & 0.19 & 0.04 \\
Total SFA & 0.07 & 0.02 \\
Total MUFA & 37.02 & 2.79 \\
Total PUFA & 33.81 & 3.85 \\
Ratio M/S & 29.17 & 5.68 \\
Ratio P/S & 0.91 & \\
$\sum \omega-3$ & 0.79 & \\
$\sum \omega-6$ & 2.64 & \\
$\sum \omega-6 / \Sigma \omega-3$ & 25.68 & \\
\hline
\end{tabular}




\section{QUALITY OF PORK MEAT}

\section{NUTRITIONAL IMPACT}

The current nutritional recommendations for the prevention and treatment of the hyperlipidaemia requires a controlled intake of saturated fat at levels below $10 \%$ of the total energy and of the dietary cholesterol lower than $300 \mathrm{mg} /$ day (NCEP,1994). Basically, these recommendations imply the reduction in the ingestion of whole dairy products and red meats. Although there are some data suggesting a bigger freedom in the consumption of those red meats with a higher content in stearic acid, as the beef tallow (Bonanome et al, 1988), for its neutral effect on the cholesterol concentrations, the Scientific Societies have not pronounced in favour of the free consumption of this type of red meats.

The studies that have analyzed the effects of the habitual intake of red meats on the lipid profile have had scarce impact on the current nutritional recommendations for the prevention of atherosclerosis. The intake of red meats, including pork meat, in comparison to the consumption of poultry meat or fish has not demonstrated that it negatively alters the lipid pattern in subjects with normolipemia (O'Brian et al, 1980 Flynn et al, 1982) nor in hyperlipidaemic patients (Gascon et al,1996, Watts et al,1988, Davison et al, 1999). Whenever the general diet is adjusted to a controlled intake of saturated fat and cholesterol and include different portions of red meats low in total fat, all the referred studies have not pointed out significant modifications in the lipid concentrations. Subjects with hyperlipidaemia, having a typically western diet, were allocated to another diet restricted in saturated fat and cholesterol, but incorporating the intake of lean red meats. The results showed a significant decrease in the levels of total cholesterol $(-8.6 \%)$ and c-LDL $(-11,1 \%)$ (Watts et al, 1988). Those data suggests that this type of lean meats can be freely incorporated in diets for the treatment of different hyperlipidaemias. In fact, these results have also been confirmed in open studies, under conditions of free-living and long-term follow-up, as the one described recently (Davison et al, 1999). This study included 191 patients with hypercholesterolemia that were assigned a diet with red meats (beef or pork) versus white meats (poultry or fish) during 36 weeks. This study did not show significant differences on the lipid profile among the two intervention groups.

The meat consumption in Spain is of $53.4 \mathrm{~kg} /$ per capita/year, being poultry meat the most consumed $(13.7 \mathrm{~kg})$, followed by pork $(10.4 \mathrm{~kg})$, beef $(7.1 \mathrm{~kg})$, and other different meats $(9.3 \mathrm{~kg})$ (MAPA, 1999). The consumption of processed pork meats (cooked and dry-cured products) is also quite important $(12.9 \mathrm{~kg})$ and follows a long tradition. However, dietary recommendations for the prevention of the hyperlipidaemia usually restricts the global consumption of pork meat (either lean or those processed meats). In these cases, poultry meats, lean cuts of veal and fish constitute an important part of the routinary diets for the control of the hyperlipidaemias.

Keeping in mind this situation, we approached a comparative study among the intake of lean veal meat and lean pork meat with less than $5 \%$ content in total fat (Porcidiet ${ }^{\circledR}$ ), in healthy volunteers to analyze their influence on the lipid profile. A controlled study, cross-over and randomized was designed. During 12 weeks of duration, 44 healthy subjects ( 22 men and 22 women) used to typical occidental diet rich in saturated fat and cholesterol, under free-living conditions, consumed during this period a diet according to the recommendations of the step 1 of the NCEP (NCEP, 1994). This diet consisted in $30 \%$ total fat, $<10 \%$ saturated fat and $<300 \mathrm{mg}$ /day of dietary cholesterol and includes a daily portion of lean veal meat ( 6 weeks) or lean pork meat ( 6 weeks). The 
preliminary results of this study shows a reduction in plasma lipids. Both types of lean meats decreased significantly the concentrations of total cholesterol (around 5\%) and triglycerides (around 6\%), without significant differences among both types of evaluated meats.

These data corroborate the results of other previously published studies and suggest that the intake of red lean meats, like pork meat, can be included in standard diets and even as a part of the therapeutic diets for the hyperlipidaemic patients.

\section{ACKNOWLEDGEMENTS}

Grants 1FD97-1864 from the Comisión Interministerial de Ciencia y Tecnología (CICYT-FEDER, Madrid, Spain) and FIS 0279/98 from Ministerio de Sanidad y Consumo (Madrid, Spain) are acknowledged. Financial support from Vaquero Foundation for $\mathrm{R}+\mathrm{D}$ on Pork Meat and Vaquero Meat Industries (Madrid, Spain) is also fully acknowledged. Porcidiet ${ }^{\circledR}$ is a registered trademark of Vaquero Meat Industries.

\section{REFERENCES}

Armero, E.; Flores, M., Toldrá, F., Barbosa, J-A., Olivet, J., Pla, M.and Baselga, M. 1999a. Effects of pig sire types and sex on carcass traits, meat quality and sensory quality of dry-cured ham. J. Sci. Food Agric., 79 $1147-1154$

Armero, E., Barbosa, J.A., Toldrá, F., Baselga, M. and Pla, M. 1999b Effects of the terminal sire type and sex on pork muscle cathepsins $(\mathrm{B}, \mathrm{B}+\mathrm{L}$ and $\mathrm{H})$, cysteine proteinase inhibitors and lipolytic enzyme activities. Meat Sci., 51: 185-189

Armero, E., Baselga, M., Aristoy, M-C. and Toldrá, F. 1999c. Effects of sire types and sex on pork muscle exopeptidase activity and the content of natural dipeptides and free amino acids. J. Sci. Food Agric., 79: $1280-1284$

Armero, E., Navarro, J.L., Nadal, M.I., Baselga, M. and Toldrá, F. 2001. Lipid composition of pork muscle as affected by sire genetic type. J. Food Biochem., submitted.

Bonanome, A. and Grundy S.M. 1988.Effect of dietary stearic acid on plasma cholesterol and lipoprotein levels. N. Engl. J. Med. ,318: 1244-1248.

Davison, M.H., Hunninghake, D., Maki K.C., Kwiterovich, P.O. and Kafonek, S. 1999. Comparison of the effects of lean red meat vs lean white meat on serum lipid levels among free-living persons with hypercholesterolemia: a long-term, randomized clinical trial. Arch. Inter. Med., 159: 1331-1338.

Flores, M., Armero, E., Aristoy, M-C. and Toldrá, F. 1999. Sensory characteristics of cooked pork loin as affected by nucleotide content and post-mortem meat quality. Meat Sci., 51: 53-59.

Flynn, M.A., Naumann, H.D., Nolph, G.B., Krause, G. and Ellersieck, M. 1982. Dietary meats and serum lipids. Am. J. Clin. Nutr., 35: 935-942.

Gandemer, G., Viau, M., Caritez, J.C. and Legault, C. 1992. Lipid composition of adipose tissue and muscle in pigs with an increasing proportion of Meishan genes. Meat Sci. 32: 105-121.

Gascon, A., Jacques, H., Moorjani, S., Deshaies, Y., Brun, L.D. and Julien, P. 1996. Plasma lipoprotein and lipolitic activities in response to the substitution of lean white fish for other animal protein sources in premenopausal women. Am. J. Clin. Nutr., 63: 315-321.

Hernández, P., Navarro, J-L. and Toldrá, F. 1998. Lipid composition and lipolytic enzyme activities in porcine skeletal muscles with different oxidative pattern. Meat Sci. 49: 1-10.

Hernández, P., Navarro, J-L. and Toldrá, F. 1999. Effect of frozen storage on lipids and lipolytic activities in the Longissimus dorsi muscle of the pig. Z. Lebensm. Unters. Forchs. A, 208: 110-115

Kauffman, R.G., Sybesma, W., Smulders, F.J.M., Eikelenboom, G., Engel, B., Van Laack, R.L.J.M., HovingBolink, A.H., Sterrenburg, P., Nordheim, E.V., Walstra, P. and Van der Waal, P.G. 1993. The effectiveness of examining early post-mortem musculature to predict ultimate pork quality. Meat Sci. 34: $283-300$

Leseigneur-Meynier, A. and Gandemer, G. 1991. Lipid composition of pork muscle as related to metabolic type of fibres. Meat Sci. 29: 229-241.

Ministerio de Agricultura, Pesca y Alimentación (MAPA). 1999. La alimentación en España. Madrid: Ministerio de Agricultura, Pesca y Alimentación. 


\section{QUALITY OF PORK MEAT}

Morgan, C.A., Noble, R.C., Cocchi, M. and McCartney, R. 1992. Manipulation of the fatty acid composition of pig meat lipids by dietary means. J. Sci. Food Agric. 58: 357-368.

National Cholesterol Education Program (NCEP). 1994. Second report of the expert Panel on Detection, Evaluation and Treatment of high blood cholesterol in adults (Adult Treatment Panel II). Circulation, 89: 1329-1445.

O’Brien, B.C. and Reiser, R. 1980. Human plasma lipid responses to red meat, poultry, fish, and eggs. Am. J. Clin. Nutr., 33: 2573-2580.

Toldrá, F., Reig, M., Hernández, P. and Navarro, J-L. 1996. Lipids from pork meat as related to a healthy diet. Recent Res. Devel. Nutr. 1: 79-86.

Toldrá, F. and Flores, M. 2000. The use of muscle enzymes as predictors of pork meat quality. Food Chem., 69: 387 395.

Tornberg, E. 1996. Biophysical aspects of meat tenderness. Meat Sci. 43: S175-S191.

Watts, G.F., Ahmed, W., Quiney, J., Houlston, R., Jackson, P. and Illes, C. 1988. Effective lipid lowering diets including lean meat. B.M.J., 296: 235-237. 